\title{
A argumentação jurídica e o ideal de racionalidade na superação de regras jurídicas
}

Alceu Mauricio Lima Junior*

\section{Introdução}

O direito é um sistema de normas que visa ao ordenamento da conduta humana. Seu objetivo é implementar a segurança e permitir a efetivação da justiça, buscando a racionalidade nas decisões pertinentes às relações intersubjetivas, notadamente naquelas em que há conflitos de interesses.

Buscar a racionalidade equivale a evitar a arbitrariedade. Até a primeira metade do século $X X$, essa exigência de racionalidade era perseguida por meio da instituição de regras jurídicas - normas imediatamente descritivas, que estabelecem obrigações, permissões e proibições através da descrição de uma conduta - cuja aplicação seria feita mediante uma lógica de subsunção, privilegiando a segurança jurídica. Porém, na medida em que a sociedade se tornou mais complexa, o direito visto como um sistema de regras não estava mais apto a atender à pretensão de racionalidade e, principalmente, de justiça. O direito passou a ser visto não só como um "direito por regras", mas também como um "direito por princípios".

A exigência de racionalidade, então, passou não mais a ser sustentada por um sistema lógico-dedutivo, mas argumentativo, que se baseia na exposição ra-

\footnotetext{
* Mestre em direito público pela Universidade do Estado do Rio de Janeiro (Uerj). Doutorando pela Pontifícia Universidade Católica do Rio de janeiro (PUC-Rio). Juiz federal no Rio de Janeiro.
} 
cional dos motivos que levaram à decisão, permitindo o seu controle e evitando a arbitrariedade.

O presente artigo analisa o fenômeno da superação da regra jurídica, em que são preenchidas as condições de aplicação da regra, todavia esta não é aplicada em razão da excepcionalidade do caso concreto ou em virtude da oposição de um princípio jurídico. Partimos da premissa de que a superação da regra é um caso excepcional e, portanto, exige maior ônus argumentativo para que se atenda ao ideal de racionalidade do direito.

Inicialmente, destacamos que a superação das regras jurídicas é um fenômeno aceito pela doutrina há bastante tempo, mesmo antes da emergência de um movimento pós-positivista, ressaltando um aparente paradoxo nessa corrente, capitaneada por Dworkin e Alexy.

Em seguida, procuramos restringir o conceito de superação jurídica, distinguindo-o de outras formas de não aplicação da regra jurídica, e destacar a diferença no modus operandi da argumentação jurídica.

Dando continuidade, expomos os requisitos para a superação de uma regra jurídica, esclarecendo o significado do maior ônus argumentativo exigido nesse caso, e propondo roteiros argumentativos para aumentar a racionalidade da decisão.

\section{O paradoxo do principialista}

Pode uma regra jurídica deixar de ser aplicada quando presentes os requisitos para sua aplicação? Ou, formulado diversamente, uma regra jurídica deve ser aplicada mesmo quando presente uma excepcional situação concreta? E que excepcionalidade justificaria a não aplicação de uma regra aplicável a priori?

Por certo, este não é um problema novo. Aristóteles, ao tratar da equidade e do equitativo, já chamava a atenção para o fato de a lei ser universal, mas não ser possível fazer uma afirmação universal que seja correta a todos os casos particulares. A lei, segundo o filósofo grego, leva em conta o caso mais frequente, mas quando surge um caso que não é abarcado por essa regra, em razão do excesso de simplicidade do legislador, é correto corrigir a omissão legal.

Sendo a equidade uma questão ligada à Justiça, não foi considerada pelo positivismo jurídico objeto próprio da ciência jurídica. Todavia, Kelsen alertava que a aplicação do direito era um ato relativamente indeterminado, fornecendo o ordenamento jurídico apenas uma moldura dentro da qual o aplicador exerce um ato de vontade. Alf Ross considera que afirmar a injustiça da norma não passa da emoção desfavorável frente a ela - “invocar a justiça é como dar uma pancada numa mesa" - , mas isso não quer dizer que não haja conexão entre o 
direito vigente e a ideia de justiça. Para Ross, embora a regularidade objetiva ou racionalidade formal seja uma ideia fundamental em todo o direito, a regra jurídica formalizada nunca pode expressar exaustivamente todas as considerações e circunstâncias relevantes e, quando se aplica a um caso individual, é possível que conduza a resultados que não podem ser aprovados pela consciência jurídica como expressão espontânea de suas valorações fundamentais. Haveria, assim, uma tensão dialética entre duas tendências opostas no direito: a tendência à generalização e a tendência à individualização. No mesmo sentido, Herbert Hart, ao apontar a textura aberta do direito, ressalta a incapacidade do legislador em antecipar todas as possíveis combinações de circunstâncias que o futuro pode trazer. De acordo com Hart, todos os sistemas chegam a um compromisso entre duas necessidades sociais:

a necessidade de certas regras que podem, sobre grandes zonas de conduta, ser aplicadas com segurança por indivíduos privados a eles próprios, sem uma orientação oficial nova ou sem ponderar as questões sociais, e a necessidade de deixar em aberto, para resolução ulterior através de uma escolha oficial e informada, questões que só podem ser adequadamente apreciadas e resolvidas quando surgem num caso concreto.

Como se pode constatar, o paradigma do positivismo jurídico cuidava da hipótese da não aplicação de uma regra prima facie aplicável, ante a excepcionalidade do caso concreto. Ronald Dworkin, contudo, ao questionar o positivismo jurídico (tomando por base o modelo de Hart), propôs uma distinção forte entre as regras e os princípios jurídicos. Regras seriam aplicadas no modo "tudo ou nada" (all-ornothing); verificada a hipótese prevista na regra, então ou a regra é válida - caso em que a consequência nela prevista deve ser observada - ou não é válida, caso em que terá contribuído em nada para a decisão. Os princípios teriam um modo de funcionamento distinto. Mesmo os que se assemelham a regras não determinam quais são as consequências legais quando as condições neles previstas são verificadas e, principalmente, os princípios teriam uma dimensão que as regras não têm: a dimensão peso ou importância. Quando princípios colidem, a solução deve ser tomada levando em conta o peso relativo de cada um. Isso não quer dizer que um princípio seja mais importante do que outro; ao contrário, um princípio pode não prevalecer na decisão de um caso concreto, mas não significa que não seja um princípio do direito, porque não só foi levado em consideração nesse caso, como também poderá ser levado em consideração - e até prevalecer - em outros casos. As regras não têm essa dimensão e, se duas regras entram em conflito, uma delas não pode ser válida. A decisão sobre qual regra será válida e qual será abandonada 
deve ser feita levando-se em consideração argumentos externos às próprias regras. Assim, um sistema jurídico pode regular os conflitos de regras por outras regras (critério hierárquico, temporal ou de especialidade) ou preferir a regra suportada por princípios mais importantes. Robert Alexy, na trilha de Dworkin, afirma que as regras seriam normas que exigem um cumprimento pleno, podendo ser cumpridas ou não. Se uma regra é válida, então é obrigatório fazer precisamente o que ela ordena, nem mais nem menos. Portanto, as regras seriam determinações no âmbito do que é fática e juridicamente possível.

A posição adotada por Dworkin e Alexy expressa um fenômeno identificado como "o paradoxo do principialista". Os que defendem a tese forte da separação entre princípios e regras costumam invocar essa posição com uma vocação antiformalista, porém nesse afã terminam por caracterizar a aplicação e a estrutura das regras com um formalismo extremo, além do que os próprios positivistas estariam dispostos a assumir.

Vários teóricos do direito apontaram essa falha na teoria dos princípios de Dworkin e Alexy, a começar por Hart que, na réplica aos ataques de Dworkin, destaca que o exemplo por este utilizado (Riggs versus Palmer) é, na verdade, um caso de superação de regras, não tendo o caráter "tudo ou nada" propalado. Peczenik, Schauer, Haage e, entre os autores brasileiros, Humberto Ávila, defendem que, mesmo sob a tese da separação forte entre princípios e regras, as últimas estão sujeitas à superação (defeasibility) e sua aplicação nem sempre é produto de uma mera subsunção, mas da ponderação de razões. Aliás, o próprio Dworkin reconheceu que às vezes uma regra se comporta como um princípio. Alexy, por outro lado, afirmou que as regras também possuem um caráter prima facie, não obstante o diferente caráter prima facie dos princípios.

Podemos afirmar que as regras jurídicas são superáveis, porém, para que a afirmação não passe de um argumento de autoridade, precisamos inicialmente definir o que é a superação de uma regra; em seguida, explicar por que uma regra jurídica é superável; por fim, como uma regra é superada no contexto de uma argumentação jurídica.

\section{Restringindo o conceito de superação de uma regra jurídica}

\section{Aplicação e não aplicação de uma regra jurídica}

As normas jurídicas - regras ou princípios - nos oferecem razões para uma ação. Dizer que uma regra jurídica foi aplicada significa que ela foi utilizada como razão para a ação que se pretende justificar. A regra então funciona como razão (ou uma das razões) para justificar a ação. 
Tomemos a regra que proíbe a prática do estupro, impondo uma sanção para o agente que a descumprir. A regra é utilizada no contexto de uma argumentação jurídica, como uma das premissas da justificação interna. Assim, partindo da premissa que praticar conjunção carnal com mulher mediante violência é crime punível com reclusão (regra), seguida da premissa que em um caso concreto o homem $\mathrm{H}$ utilizou violência para forçar a mulher $\mathrm{M}$ a praticar com ele conjunção carnal (situação de fato), podemos concluir que H praticou o crime de estupro, devendo ser condenado à pena prevista na regra. $\mathrm{O}$ policial que prende $\mathrm{H}$ em flagrante, o juiz que o condena na sentença, e o tribunal que confirma a sentença em grau de recurso, todos aplicam a regra que prevê o crime de estupro, ou seja, utilizam-na como razão para justificar suas ações ou decisões.

Tal modelo, todavia, apenas espelha a reconstrução lógica da argumentação jurídica. O discurso jurídico, porém, não se desenvolve normalmente de uma forma linear, mas de forma circular. $\mathrm{O}$ operador do direito inicialmente tem contato com o fato concreto, depois propõe a regra aplicável ao caso, e por fim volta ao caso para analisar se ele realmente se conforma na hipótese prevista na regra. Esse é o encadeamento denominado círculo hermenêutico. É claro que quem apela para uma regra no curso da apresentação de um argumento justificativo ao menos está pressupondo que as condições para sua aplicação foram atendidas.

Nem sempre a regra preliminarmente proposta no discurso jurídico para justificar a ação a ser tomada conforma perfeitamente o caso concreto. No desenvolvimento do círculo hermenêutico, o operador do direito pode visualizar outra regra ou fato (a prescrição da pretensão punitiva, por exemplo) que inviabilize a adoção da regra inicialmente proposta para a solução do caso. O resultado é que a regra inicialmente proposta não se presta a justificar a ação tomada (a absolvição do agente). Em outras palavras, a regra não foi aplicada.

Podemos concluir que a não aplicação de uma regra jurídica é o fenômeno em que uma regra - proposta no âmbito do discurso jurídico como potencialmente capaz de justificar a ação a ser tomada - não é utilizada, pelo aplicador do direito, como justificativa para sua ação.

O que pretendemos demonstrar é que a superação de uma regra é um caso de não-aplicação, porém não o único. Há outras formas de não aplicação de regras jurídicas que têm origens distintas e, principalmente, requerem argumentações distintas, o que justifica a diferenciação que estamos propondo. Para isso, construímos um raciocínio inverso em relação às condições para a aplicação de uma regra jurídica (a validade, a existência, a eficácia e a incidência). 


\title{
Formas de não aplicação de uma regra jurídica
}

\author{
Invalidade
}

A validade é a qualidade da regra jurídica consistente na sua adequação formal e material ao ordenamento jurídico. Regra válida é aquela formada de acordo com o processo constitucionalmente estabelecido, dentro da distribuição constitucional de competências, e em consonância com as normas hierarquicamente superiores. Pelo raciocínio inverso, regra inválida é aquela que se formou não de acordo com o procedimento previsto, não emanou do órgão competente, ou então contrariou normas hierarquicamente superiores.

Não são raros os exemplos em que uma regra não é aplicada em razão de sua invalidade, como na ADI no 1.689/PE, em que o STF julgou inconstitucional o art. 227, parágrafo único, da Constituição do estado do Espírito Santo. Este dispositivo previa a aplicação de percentual mínimo do orçamento estadual para a promoção de programas de assistência à criança e ao adolescente, porém o STF entendeu que essa norma violava o disposto no art. 167, IV, da CF, que veda a vinculação de receitas, salvo as vinculações expressamente previstas na própria $\mathrm{CF} .{ }^{1} \mathrm{~A}$ regra estadual violava norma de hierarquia superior, sendo portanto inválida.

\section{Inexistência}

A existência também é uma qualidade da regra jurídica. Considerando que as regras jurídicas são introduzidas no ordenamento por meio de um ato estatal, elas são existentes quando o ato que as institui reúne os requisitos necessários à sua formação, como a manifestação de vontade do órgão competente.

A inexistência aproxima-se da invalidade, mas podemos identificar casos específicos de inexistência. Aproveitando o exemplo de Barroso, "seria inexistente, por exemplo, uma 'lei' que não houvesse resultado de aprovação da Casa Legislativa, por ausente a manifestação de vontade apta a fazê-la ingressar no mundo jurídico". Esse foi exatamente o caso verificado no Habeas Corpus oㅜ 77.724/SP. O art. 11 da Lei no 9.639/98 concedeu anistia aos agentes políticos responsabilizados, sem que fosse atribuição legal sua, pelo crime de apropriação indébita previdenciária (art. 95, $d$, da Lei no 8.212/91). O artigo foi votado sem parágrafos, mas, no texto enviado para sanção ao presidente e posteriormente publicado, constou um

\footnotetext{
${ }^{1}$ STF. ADI 1.689/PE, Pleno, rel. min. Sydney Sanches, unanimidade, RTJ 185/487.
} 
parágrafo único, estendendo a anistia aos demais responsabilizados pela prática daquele delito. No julgamento, o STF concluiu pela inconstitucionalidade do referido parágrafo único por falta da manifestação do Poder Legislativo, o que pode ser traduzido como vício de inexistência. ${ }^{2}$

\section{Ineficácia}

Também uma qualidade da regra, a eficácia é a aptidão para a produção de efeitos, na idoneidade para atingir a finalidade para a qual foi gerada.

A ineficácia da regra pode ser oriunda de uma condição inerente ao ato que a introduz no ordenamento jurídico (a vactio legis, por exemplo), ou por razão de um elemento externo, como a falta de uma norma reguladora. Exemplo deste último caso materializou-se na interpretação dada pelo STF à regra contida no art. 37, VII, da CF, a respeito do direito de greve dos funcionários públicos. O tribunal entendeu que a regra não era autoaplicável (eficaz) por falta de norma regulamentadora. ${ }^{3}$

\section{Características comuns à não aplicação por invalidade, inexistência e ineficácia}

Nos três casos citados, a regra jurídica não foi aplicada porque o tribunal considerou que pelo menos um dos requisitos de aplicação não estava satisfeito. Isso também pode acontecer com a incidência. Todavia, a argumentação jurídica no caso de não aplicação da regra por invalidade, inexistência ou ineficácia tem peculiaridades que exigem destaque.

Em primeiro lugar, não é levado em consideração se um fato concreto se enquadra na hipótese prevista na regra; quando muito, os fatos levados em conta na argumentação dizem respeito a questões externas à hipótese de incidência. Em outras palavras, não se faz a avaliação da correspondência entre a construção conceitual dos fatos e a construção conceitual da norma. ${ }^{4}$

\footnotetext{
${ }^{2}$ STF. HC 77.724/SP, Pleno, rel. min. Marco Aurélio, unanimidade, RTJ 177/329.

${ }^{3}$ Vide, entre outros, STF, MI 485/MT, Pleno, rel. ministro Maurício Corrêa, unanimidade, RTJ 186/28.

${ }^{4}$ Aqui precisamos fazer uma observação à proposta de Humberto Ávila. O autor afirma que a justificação exigida para a aplicação da regra jurídica consiste na avaliação da correspondência entre a construção conceitual dos fatos e a construção conceitual da norma, porém, como vimos, a justificação da aplicação da regra exige a consideração de outros elementos externos, como a validade, existência e a eficácia, que são estranhos à justificação dos princípios jurídicos, já que estes dispensam a instituição através de um órgão estatal. Veja-se, por exemplo, o princípio da segurança jurídica, inerente ao estado
} 
Em segundo lugar, por decorrência do que foi afirmado, invalidade, ineficácia e inexistência da regra podem ser apuradas em abstrato.

Por fim, são utilizados apenas argumentos institucionais. ${ }^{5}$

\section{Não incidência}

\section{NÃO INCIDÊNCIA SIMPLES}

A incidência não é uma qualidade, mas fenômeno ${ }^{6}$ pertinente à regra jurídica, que se traduz na ocorrência de um fato que se amolda à previsão nela estabelecida. Conforme Pontes de Miranda, cada regra de direito enuncia algo sobre fatos e, se esses fatos se produzem, sobre eles incide a regra ou, em outras palavras, quando o suporte fático suficiente ocorre, a regra jurídica incide.

A incidência - assim como a validade, a eficácia e a existência - é um requisito para a aplicação da regra. Se uma regra, colocada no contexto de uma argumentação jurídica com pretensão de justificar a decisão a ser tomada, é considerada não incidente no caso concreto, a decorrência lógica é sua não aplicação.

Um exemplo de não aplicação por não incidência pode ser colhido no julgamento do RE no 219.983/SP, em que se discutiu a propriedade da União sobre antigos aldeamentos indígenas. Entendeu o STF que as terras ocupadas por indígenas em passado remoto não se enquadravam na previsão normativa da regra contida nos incisos I e XI do art. 20 da CF. ${ }^{7}$

Tal caso é o que consideramos não incidência simples, pois o tribunal chegou a essa conclusão apenas por não vislumbrar a correspondência entre os fatos e a norma, não avaliando a incidência de outra regra ou princípio que a afastasse nem a excepcionalidade do fato.

\footnotetext{
de direito, porém não enunciado. Nem por isso, a questão de validade entra no contexto da justificação do princípio.

${ }^{5}$ De acordo com Humberto Ávila, argumentos institucionais são aqueles que, por serem determinados por atos institucionais, têm como ponto de referência o ordenamento jurídico, possuindo maior capacidade de objetivação, ao contrário dos argumentos não institucionais, que possuem menor capacidade de objetivação por serem decorrentes apenas do apelo ao sentimento de justiça

${ }^{6}$ Geraldo Ataliba também considera a incidência um fenômeno. Diz o doutrinador que "costuma-se designar por incidência o fenômeno especificamente jurídico da subsunção de um fato à hipótese legal, como consequente e automática comunicação ao fato das virtudes jurídicas previstas na norma".

${ }^{7}$ STF. RE 219.983/SP, Pleno, rel. min. Marco Aurélio, unanimidade, RTJ 171/338.
} 


\section{NÃO INCIDÊNCIA QUALIFICADA PELA INCIDÊNCIA DE UMA REGRA DE EXCEÇÃO}

A não incidência qualificada pela incidência de uma regra de exceção é, na verdade, uma dupla incidência. A regra inicialmente colocada com pretensão de justificar a decisão final reúne prima facie todos os elementos para sua aplicação, contudo também incide outra regra, que acaba afastando a incidência da primeira, gerando sua não aplicação. Mas o que acontece nesse caso? Uma das regras é revogada parcialmente ou ambas coexistem?

Esse fenômeno pode ser explicado pela derrogação. Segundo Novelli, citando Rescigno, a derrogação é uma palavra que também pode ser entendida no sentido de designar "o efeito jurídico em virtude de que uma norma superveniente exclui, relativamente a uma hipótese específica, a força qualificatória de uma norma anterior, que permanece em vigor com respeito às hipóteses genéricas por esta última, anteriormente previstas". Na derrogação, ao contrário da ab-rogação, a norma derrogada permanece em vigor, ainda que em um âmbito mais limitado, e, cessando a norma derrogante, a norma derrogada disciplina desde logo tudo o que virtualmente podia disciplinar.

Elucidativa é a lição de Larenz, quando identifica a existência de proposições jurídicas restritivas. Certas proposições jurídicas, por vezes, estão conformadas de modo tão amplo que, segundo o seu sentido literal, abarcariam situações de fato para as quais não devem valer. Nesse caso, as proposições jurídicas são restringidas por outras proposições jurídicas, que só se tornam compreensíveis em conjugação com uma ordenação de vigência precedente. Assim, as proposições jurídicas não são apenas um conjunto de normas colocadas umas ao lado das outras, mas estão relacionadas entre si, e só na sua recíproca delimitação e no seu jogo é que produzem uma regulação.

Analisando o concurso de proposições jurídicas, Larenz observa que, se as normas são do mesmo nível hierárquico, deve ser verificado se entre elas há uma "relação lógica de especialidade". Não é exata, para Larenz, a conclusão de que a norma especial afasta sempre, no seu âmbito de aplicação, a norma geral. Só quando as consequências jurídicas se excluem é que a relação de especialidade conduz necessariamente ao afastamento da norma mais geral.

O critério da especialidade também encontra registro na Lei de Introdução do Código Civil (LICC) que, em seu art. 2oㅗ § 2o, diz: "A lei nova, que estabeleça disposições gerais ou especiais a par das já existentes, não revoga nem modifica a lei anterior". Esse critério não serve apenas para fazer prevalecer as disposições de uma norma anterior mais específica quando confrontadas com uma norma posterior mais genérica, mas também para preservar normas gerais anteriores de leis novas que regulem um caso específico. Nessa hipótese, o critério da especialidade serve para circunscrever o âmbito de aplicação da norma especial mais recente, 
mantendo a lei geral anterior para os casos não especificamente regulados pela nova legislação.

Vamos examinar o exemplo trazido por Ávila. Veja-se o caso em que uma lei proíbe a concessão de liminar contra a Fazenda Pública que esgote o objeto litigioso (Lei no 9.494/97), e que outra lei determine que o Estado deve fornecer medicamentos excepcionais para pessoas que não puderem prover as despesas com os referidos medicamentos (Lei no 9.908/00). Destes enunciados poderíamos extrair proposições contraditórias (o juiz não deve conceder liminar para entrega de medicamentos e o juiz deve conceder liminar para o fornecimento de medicamentos), gerando uma antinomia, porém a antinomia é apenas aparente. A Lei no 9.908 gera uma proposição jurídica especial, fazendo com que a Lei oㅜ 9.494 não se aplique aos casos de fornecimento de remédios. Em suma, cria-se uma derrogação à norma geral, que não a invalida, mas apenas reduz seu âmbito. Se a Lei no 9.908 fosse revogada, a Lei no 9.494 voltaria a ter sua amplitude original.

Portanto, no caso de conflitos de regras, se tivermos uma antinomia real, fatalmente haverá a perda de validade de uma delas. Se a antinomia for aparente, ambas as regras permanecem válidas, reduzindo-se a amplitude da norma mais geral, derrogada pela especial. Como diz Larenz, "não aplicamos normas jurídicas isoladas, mas, na maioria das vezes, aplicamos uma regulação global".

Com argumentos semelhantes, Dworkin procura afastar as críticas de Joseph Raz, pois o exemplo que este traz para refutar a tese do primeiro enquadrava-se exatamente no caso que denominamos não incidência qualificada pela incidência de uma regra de exceção.

\section{ASPECTOS RELATIVOS À ARGUMENTAÇÃO NA NÃO APLICAÇÃO DA REGRA EM VIRTUDE DA NÃO INCIDÊNCIA}

Ao contrário dos casos anteriores (invalidade, ineficácia e inexistência), na não incidência é realizada a avaliação da correspondência entre a construção conceitual dos fatos e a construção conceitual da norma. Por isso, só se pode falar em não incidência diante de um caso concreto. Também neste caso o afastamento da regra se vale apenas de argumentos institucionais. A diferença entre a não incidência simples e a qualificada pela incidência de uma regra de exceção é que na segunda, além da avaliação de correspondência entre o fato e a norma, também deve ser avaliada a correspondência entre o fato e a regra de exceção.

Por essa característica, a argumentação jurídica na avaliação da incidência torna-se mais complexa, levando-se em conta que surgem todas as dificuldades inerentes à prova dos fatos, usualmente dispensadas nos demais casos que vimos, pois em geral o direito positivo independe de prova. ${ }^{8}$

\footnotetext{
${ }^{8}$ Desta forma, quando se avalia se uma regra é válida, eficaz e existente, as questões de fato são irrelevantes ou acidentais, em geral dispensando a produção de provas. O que se faz nesses casos, na
} 


\section{A superação da regra jurídica}

\section{Delimitando a ideia de superação da regra jurídica}

Em todas as hipóteses até aqui explicadas, podemos observar um ponto comum em termos de argumentação jurídica: a utilização exclusiva de argumentos institucionais para o afastamento da regra. Em todos esses casos houve a proposta de aplicação da regra jurídica, mas esta não foi utilizada como razão para a ação ou decisão porque outro argumento institucional foi contraposto (uma regra de competência ou procedimental, a falta de regra de regulamentação, a não correspondência entre o fato e a própria regra, ou a correspondência do fato à previsão contida em regra de exceção).

Poderíamos dizer que em todos esses casos a regra foi "derrotada". Aliás, um dos exemplos que Haage propõe para demonstrar a propensão ao "derrotamento" (defeseability) das regras é o da incidência de uma regra de exceção. ${ }^{9}$ Entretanto, não são esses os casos que entendemos por superação da regra, pelo menos não em um sentido estrito. ${ }^{10}$

A superação da regra é o fenômeno pelo qual a regra reúne todos os requisitos para sua aplicação (é válida, existente, eficaz e existe a correspondência entre o fato concreto e a hipótese de incidência prevista na regra) e não há a incidência de uma regra de exceção, porém mesmo assim a regra não é aplicada. Observe-se que a superação é um fenômeno bem mais estrito do que os casos já analisados e, aparentemente, provoca uma "quebra" no sistema, pois vai buscar sua justificação final em argumentos consequencialistas ou, segundo a nomenclatura de Ávila, não institucionais.

Vejamos o exemplo que Ávila traz para criticar o critério do "modo final de aplicação". Pelo art. 224 do Código Penal se estabelece uma presunção absoluta de violência quando a vítima é menor de 14 anos, e a lei não traz qualquer exceção a essa regra. Apesar disso, o Supremo Tribunal Federal afastou essa presunção em

\footnotetext{
verdade, é uma avaliação lógica, tomando por objeto as próprias normas existentes no direito positivo e não fatos empiricamente observados.

${ }^{9} \mathrm{O}$ exemplo é o seguinte: existe uma regra que determina que todo criminoso deve ser punido; John é criminoso, logo deveria ser punido; porém, o crime de John está prescrito; neste caso a regra que determina que todo criminoso deve ser punido não se aplica a John, muito embora tenha reunido todas as condições para sua aplicação.

${ }^{10}$ Haage até contrapõe o argumento da falta de especificação da regra inicialmente proposta, mas recusa esta resposta alegando que a regra completa (regra inicial + regra de exceção) foi, na verdade, construída ao final, após a decisão. De fato, a regra completa aplicável ao caso só é identificada ao final do discurso, porém a argumentação jurídica tem sua atenção focada para o contexto da justificação e a regra completa pode muito bem ser visualizada, a priori, com elementos dentro do próprio sistema, conforme a lição de Larenz já descrita.
} 
um caso concreto, no qual a vítima tinha 12 anos, concordou com o ato, e tinha aparência física e mental de pessoa mais velha. Logo, embora os requisitos normativos expressos estivessem presentes, a norma não foi aplicada. ${ }^{11}$

Esse é um caso de superação da regra jurídica, pois ela é afastada não pelo recurso a um argumento sistemático, mas consequencialista. Os argumentos sistemáticos indicavam a aplicação da regra, mas se ela fosse aplicada geraria no plano empírico uma consequência exorbitante, não razoável, além dos fins previstos pela própria regra, ou ainda contrária aos fins determinados por outros princípios.

A superação de uma regra ocorre diante de um caso difícil, porém nem todo caso difícil é de superação de uma regra. Não há uma correspondência biunívoca entre casos difíceis e superação de regras. Seguindo a divisão quadripartite de casos difíceis propostos por MacCormick, eles se relacionam a problemas de interpretação, de pertinência, de prova e de qualificação. Os dois primeiros afastam a premissa normativa e os dois últimos a premissa fática da regra.

O problema de interpretação existe quando não há dúvida quanto à norma aplicável, mas a norma em questão admite mais de uma leitura. Esse seria, por exemplo, o caso do RE no 219.983/SP já visto, que discutiu se as terras ocupadas por indígenas em passado remoto se enquadravam na previsão normativa da regra contida nos incisos I e XI do art. 20 da CF. Problemas de pertinência seriam anteriores à interpretação, discutindo-se se há uma norma aplicável ao caso, ou mesmo a validade, existência e eficácia da norma, como nos exemplos já descritos. Os problemas de prova são relativos ao estabelecimento da premissa menor da regra; se os fatos previstos hipoteticamente na regra correspondem a um acontecimento empiricamente observado. Já os problemas de qualificação ou "fatos secundários" ocorrem quando não há dúvidas sobre a existência de certos fatos primários, mas o que se discute é se eles integram ou não um caso que pode ser subsumido na regra.

Embora haja equivalência lógica entre problemas de interpretação e de qualificação, a distinção se mantém por razões de tipo processual relacionadas com a distinção entre questões de fato e de direito, tais como o acesso a instâncias recursais e a formação de precedentes. No ordenamento jurídico brasileiro, por exemplo, o reexame de prova não dá ensejo aos recursos especial e extraordinário. ${ }^{12} \mathrm{O}$ afastamento da regra em razão da excepcionalidade de uma circunstância ligada ao fato principal prejudica, ou dificulta, a formação de um precedente para casos futuros. Vejamos, por exemplo, o caso do HC no $81.268 /$ DF. $^{13}$ Neste HC, arguiu-se perante o STF que, de acordo com as razões adotadas no

\footnotetext{
${ }^{11}$ STF. HC 73.662/MG, 2aㅡ Turma, rel. min. Marco Aurélio, por maioria, RTJ 163/1028.

${ }^{12}$ Vide súmulas 279 do STF e 7 do STJ.

${ }^{13}$ STF. HC 81.268-6/DF, $1^{\text {a }}$ Turma, rel. min. Sepúlveda Pertence, unanimidade, RTJ 180/315.
} 
HC no 73.662, ${ }^{14}$ a presunção de violência contida no art. 224 do CP não era mais considerada absoluta. Todavia, o STF rechaçou a tese do paciente, confirmando o caráter absoluto daquela presunção, bem como sua constitucionalidade. No voto condutor, de lavra do ministro Sepúlveda Pertence, destacou-se que o HC no 73.662 foi um caso isolado, havendo julgados em contrário em ambas as turmas do STF. Permanecia, entretanto, a possibilidade de afastamento da regra em virtude de justificado erro de fato sobre a idade da vítima, que precisamente foi o que restou, comprovado no HC no 73.662 .

Assim, podemos concluir que os problemas de superação de regras são de qualificação. São problemas ligados à existência de um fato. Não o fato previsto na norma, pois sobre este não há dúvidas da ocorrência, mas da existência de outro fato (ou de uma característica excepcional daquele fato) que cria uma exceção ad hoc para a regra, sob o apelo de uma razão de justiça ou de razoabilidade.

Mas, se uma regra é válida e eficaz, não há dúvidas quanto ao enquadramento do fato à hipótese normativa, e não há regras de exceção incidentes, por que então a regra não é aplicada? Por que, então, as regras são superáveis?

\section{Regras como generalizações e modelos para tomar decisões a partir de regras}

A superação de uma regra tem raiz no seu próprio mecanismo de formação. Estabelecer regras é criar uma generalização, pois elas se dirigem a "tipos", e não a casos particulares. Na generalização existe uma escolha de como definir as classes em que vou agrupar os fatos, objeto da regra. Essa escolha é seletiva na inclusão das características relevantes, mas também é exclusiva, pois afasta outras possíveis generalizações. A justificação da regra é que vai determinar qual, entre as possíveis generalizações, vai ser adotada, pois a generalização tem uma relação probabilística de causalidade com a justificação. Porém três problemas surgem da generalização. Primeiro, nem sempre a generalização (a hipótese) dá causa à consequência que justifica a regra (over-inclusive). Por outro lado, a hipótese por vezes não cobre certos fatos que provocam a consequência que justifica a regra (under-inclusive). Mesmo que a hipótese seja precisa, a regra ainda é potencialmente imprecisa por conta da textura aberta (open texture).

A generalização formulada na regra encontra falhas, provocando experiências recalcitrantes. $\mathrm{O}$ que fazer? Schauer aponta dois possíveis modelos para

\footnotetext{
${ }^{14}$ STF. HC 73.662/MG, 2ª Turma, rel. min. Marco Aurélio, por maioria, RTJ 163/1028.
} 
lidar com o problema. Poderíamos adotar um modelo conversacional, com uma contínua adaptação da regra às necessidades do momento sempre que surge uma disjunção, ou então um modelo entrincheirado, no qual a ocorrência da experiência recalcitrante não reformula a generalização, ou seja, a generalização controla a decisão mesmo nos casos em que falha ao servir à justificação subjacente. As regras, para Schauer, funcionam como generalizações entrincheiradas, pois a simples ocorrência de uma experiência recalcitrante não é suficiente para afastar a generalização contida na norma. Esse entrincheiramento das regras provém tanto de sua autonomia semântica como de sua institucionalização por uma autoridade.

Daí Schauer apresenta três modelos de tomada de decisão a partir de regras. No modelo particularista, as regras seriam absolutamente transparentes, permitindo ao aplicador levar em conta todas as possíveis considerações morais sobre o caso. No modelo baseado em regras, elas se apresentam de forma absolutamente opaca, não permitindo a consideração de outras razões. As regras, nesse modelo, são razões protegidas, peremptórias, finais. Para o seguimento da regra, além das razões de $1^{a}$ ordem (que dão justificação ao conteúdo da regra) há razões de $2^{a}$ ordem (que justificam a institucionalização das razões de $1^{\underline{a}}$ ordem por meio de uma regra) excludentes. Os dois modelos projetam generalizações do passado sobre realidades do futuro, mas diferem na presença de uma experiência recalcitrante. Nesse caso, o modelo particularista adapta a generalização à realidade presente, e o modelo baseado em regras rejeita essa adaptação, pois as razões de $2^{\underline{a}}$ ordem excluem outras possíveis razões de $1^{\underline{a}}$ ordem diferentes das que sustentam a regra.

Schauer defende um modelo intermediário, que denomina particularista sensível às regras, que presta atenção não só na razão que fundamenta a regra (1ª ordem), mas também na própria razão de instituir a regra (rule-generating justification). No positivismo presuntivo de Schauer, as regras têm uma pretensão de decidibilidade. Gozam de uma prioridade forte, porém superável (overridable). A força da regra se assenta no fato de que, para superá-la, não basta prover razões contrárias às razões subjacentes à regra, mas também razões contrárias às que levaram à instituição da regra.

O modelo proposto por Schauer tem mais consistência para explicar o papel das regras em um discurso jurídico. As regras fornecem razões prima facie, que podem ser sopesadas por outras razões, mas não só razões de $1^{a}$ a ordem, mas também razões de $2 \stackrel{a}{a}$ ordem. Estas indicam que as razões para não seguir a regra só podem prevalecer se forem particularmente fortes, "claramente mais fortes do que necessitam ser em um debate moral livre". 


\section{Requisitos para a superação de uma regra jurídica}

Como vimos, a regra jurídica é superável, porém essa operação requer justificação precisa, não podendo o aplicador do direito simplesmente desconsiderar as decisões prévias feitas pela autoridade à qual a Constituição atribuiu competência para instituir aquela regra jurídica. A superação das regras requer a demonstração de que a excepcionalidade do caso exige que o sistema jurídico positivo seja colocado em um segundo plano e que se busque uma solução específica extrassistema para resolvê-lo. Essa demonstração ou justificação pode estar baseada na própria finalidade subjacente à regra ou nos princípios superiores a ela.

\section{Superação em razão da finalidade subjacente à regra}

\section{A redução teleológica}

A ideia de uma regra superável pela excepcionalidade do caso concreto nos remete à ideia de lacuna da lei. Larenz chama a atenção para as denominadas "lacunas ocultas", ou seja, os casos em que "uma regra legal, contra o seu sentido literal, mas de acordo com a teleologia imanente à lei, precisa de uma restrição que não está contida no texto legal". Para integrar essa lacuna, acrescenta-se uma restrição - denominada "redução teleológica" - requerida em conformidade com o fim previsto na lei. Justifica-se no imperativo da justiça de tratar desigualmente os desiguais, e pode ser prevista pelo fim visado na própria regra, pela "natureza das coisas", ou por um princípio. Perelman, observando o mesmo fenômeno, destaca os casos em que o intérprete, desejando evitar a aplicação da lei em dada espécie, restringe-lhe o alcance, criando uma lacuna "contra legem". ${ }^{15}$

No caso do afastamento da presunção de violência do art. 224 do CP, realizada no HC no 73.662, o STF se valeu de um raciocínio que pode ser reconstruído pela redução teleológica. De acordo com a teleologia imanente à lei penal em questão, o Supremo Tribunal entendeu que aquela norma precisava de uma restrição que não estava contida no texto do dispositivo, havendo uma "lacuna oculta". Para integrar essa lacuna, acrescentou-se uma restrição, que poderia ser assim enunciada: a presunção do art. 224 do Código Penal não prevalece quando a vítima, mesmo menor de 14 anos, concorda com o ato e, pela sua aparência e experiência, induz o autor a acreditar que já tem uma idade superior.

\footnotetext{
${ }^{15}$ Por coincidência, o exemplo trazido por Perelman é o de um atentado violento ao pudor cometido contra pessoa francesa de 13 anos, sem violência nem ameaça.
} 


\section{postulado da razoabilidade}

Outra forma de reconstruirmos a decisão tomada pelo STF no HC nº 73.662 é pelo postulado da razoabilidade. Segundo Ávila, o postulado da razoabilidade estrutura a aplicação de outras normas, podendo ser utilizado em vários sentidos, entre os quais servir de diretriz que exige a relação das normas gerais com as individualidades do caso concreto (razoabilidade como equidade). Assim, a razoabilidade impõe a consideração daquilo que normalmente acontece, não se presumindo o que é extraordinário e, também, a consideração do aspecto individual do caso nas hipóteses em que ele é desconsiderado pela generalização legal.

Podemos então reconstruir a decisão do STF da seguinte forma: o caso concreto descrito no $\mathrm{HC}$ no 73.662 é, em relação à previsão normativa do art. 224 do $\mathrm{CP}$, um caso anormal, não sendo consideradas pela regra especificidades relevantes, como a aparência e a experiência da menor de 14 anos, que efetivamente induziram em erro o agente.

\section{Ônus argumentativo na superação da regra através da redução teleológica ou do postulado da razoabilidade}

A exposição dos mecanismos de superação da regra pela redução teleológica ou do postulado da razoabilidade demonstra a grande semelhança entre os dois modelos. Mas a grande questão ainda permanece: se a superação da regra jurídica em nosso ordenamento não pode ser uma mera preferência do aplicador, como justificá-la?

A aplicação de uma regra requer um "ônus argumentativo menor, na medida em que a descrição normativa serve, por si só, como justificação" e, por outro lado, para sua superação, exige-se um "ônus argumentativo maior". Entretanto, em que consiste esse maior ônus argumentativo quando pretendemos superar a regra através da redução teleológica ou do postulado da razoabilidade?

A superação da regra exige recurso a argumentos não institucionais ou consequencialistas, e é um problema de qualificação. Logo, é um problema ligado à existência de um fato. Não do fato previsto na norma, pois sobre este não há dúvidas da ocorrência, mas da existência de um outro fato (ou de uma característica excepcional daquele fato) que cria uma exceção ad hoc para a regra sob o apelo de uma razão de justiça ou de razoabilidade.

Daí podemos retirar as seguintes exigências:

a questão de fato que excepciona a regra deve ser anormal em relação à generalização contida na regra; 
a ocorrência do fato excepcional torna nula ou diminuta a relação de causalidade entre a situação concreta e a justificação da regra;

a questão de fato excepcional que é colocada para justificar a superação da regra deve estar suficientemente comprovada.

Para se superar uma regra, primeiramente deve ser demonstrado que a situação de fato apresenta uma característica que a coloca fora do padrão de normalidade dos fatos utilizados para a generalização utilizada na regra. Vejamos novamente o caso do $\mathrm{HC}$ nำ 73.662. A regra do art. 224 do CP faz uma generalização levando em conta um padrão normal de comportamento e capacidade de discernimento de adolescentes e crianças. De acordo com essa generalização, menores de 14 anos não teriam desenvolvimento mental suficiente para dar consentimento para a prática de um ato sexual. Por isso, a regra proíbe que agentes capazes pratiquem atos sexuais com menores de 14 anos, mesmo que estes deem consentimento para o ato. No caso concreto, porém, a menor de 14 não só deu consentimento como tinha experiência e aparência de pessoa mais velha, induzindo o acusado ao erro quanto a uma situação de fato.

A justificação da regra é preservar a liberdade sexual dos menores de 14 anos, pois não teriam discernimento para consentir na prática de um ato sexual. No caso concreto, entretanto, a menor de 14 anos já possuía experiência sexual. A aplicação da regra do art. 224 do CP, então, não teria o efeito de alcançar o estado de coisas cujo atendimento estaria suportando essa norma.

Não basta simplesmente alegar o fato excepcional, mas também é necessário prová-lo. Essa parece ser uma exigência óbvia, mas é de sua inobservância que advêm boa parte dos erros judiciários, que simplesmente adaptam precedentes judiciais sem atentar para a existência da correspondência da situação de fato do precedente com a comprovada situação de fato do caso em análise. Atentando para tal exigência, o STF deixou de adotar as razões contidas no HC no 73.662 em casos posteriores, como o do $\mathrm{HC}$ no 81.268 referido.

Há, todavia, mais uma exigência que deve ser formulada para a superação da regra no modelo ora analisado. $\mathrm{O}$ afastamento da regra pelo atendimento apenas das condições acima levaria a um resultado que, a princípio, seria mais justo do que seguir a regra, mas há também uma relevância moral em se seguir o direito positivo. ${ }^{16}$ A força do ideal de justiça deve se mostrar no caso concreto maior do que as razões de segunda ordem que levaram ao estabelecimento da regra. Isso pode ser verificado quando se demonstra que estado de coisas resultante da aplicação da regra termina por ser mais prejudicial à coerência do sistema jurídico do

\footnotetext{
${ }^{16}$ Sobre a relevância moral de seguir o direito, vide Peczenik.
} 
que a sua superação. ${ }^{17}$ No HC no 73.662, essa exigência foi cumprida, pois o erro do acusado sobre a idade da vítima retirava-lhe a intenção de praticar a conduta com uma menor de 14 anos, e condenar alguém sem intenção por um crime cujo tipo não prevê a modalidade culposa provoca no sistema jurídico uma quebra de coerência maior do que a própria não aplicação da regra. Sob outro ângulo, como o caso excepcional foge ao padrão de normalidade da generalização utilizada na regra, a aplicação dessa regra teria os mesmos efeitos de uma aplicação por analogia, o que é vedado no direito penal. Observe-se, entretanto, que essa exigência não foi atendida no caso do $\mathrm{HC}_{\mathrm{n}} \mathrm{o}$ 81.268, gerando o indeferimento do pedido.

Formulamos, então, a quarta exigência:

o estado de coisas resultante da aplicação da regra termina por ser mais prejudicial à coerência do sistema jurídico do que a sua superação.

\section{O confronto com um principio superior}

\section{O modelo de superação da regra através da contraposição de um princípio jurídico}

A superação de uma regra também pode ser justificada pelo recurso a um princípio superior. Nesse caso, a aplicação da regra conduz a um estado de coisas que se opõe ao estado de coisas perseguido por outro princípio. A aplicação da regra promove os fins determinados pelo princípio que lhe dá sustentação, mas no caso concreto há princípios que fornecem razões para a não aplicação. Há, portanto, um confronto entre o princípio que dá sustentação à regra e outro princípio do sistema jurídico.

Em última análise, quase todo caso de não aplicação de uma regra pode ser reconduzido ao confronto entre princípios de hierarquia superior. ${ }^{18}$ Isso não chega a ser um problema, desde que obedecidos os critérios próprios desse modelo. Vejamos novamente o caso do $\mathrm{HC}$ n 73.662. Poderíamos reconstruir a decisão do STF através da contraposição de um princípio. O princípio que sustenta a regra do art. 224 do CP é o que dá proteção à criança e ao adolescente, que se extrai do art. 227 da CF. Em contraposição, poderíamos listar os princípios do devido processo legal, da ampla defesa e da presunção de inocência (art. 5ㅜ, LIV, LV, LVII). Naquela ação prevaleceram os princípios opostos ao que dava fundamentação ao art. 224

\footnotetext{
${ }^{17}$ Tomamos aqui um conceito de coerência mais amplo a que se refere Hage.

${ }^{18}$ Seriam exceções as regras contidas na própria Constituição, partindo do pressuposto de inexistência de hierarquia entre as normas constitucionais.
} 
do CP. No HC nº 81.268, ao contrário, prevaleceu o princípio da proteção à criança e ao adolescente e, por conseguinte, prevaleceu a regra do art. 224 do CP.

Outro exemplo de superação de uma regra por um princípio está na Intervenção Federal (IF) no 2.915-5/SP. Nesta ação, requeria-se a intervenção no estado de São Paulo pelo não pagamento de precatórios, inclusive alimentares, resultantes de condenações judiciais. O pedido era embasado na regra contida no art. 34, VI, que autoriza a intervenção federal por descumprimento de ordem judicial. Porém, de acordo com o voto do ministro Gilmar Mendes, prevaleciam os princípios da não intervenção e da autonomia federativa, levando em conta a necessidade de atendimento de outras normas constitucionais, tais como a prestação de serviços públicos e a escassez de recursos. ${ }^{19}$

Para resolver o confronto entre o princípio que sustenta a regra e o princípio que está em oposição, adota-se o critério da ponderação. A característica que se destaca na superação de uma regra é que não basta sopesar os princípios que se confrontam, sob pena de aceitar-se a premissa da irrelevância moral do direito positivo, o que permitiria ao intérprete, em cada caso, refazer a ponderação entre os princípios que influenciam a decisão sem levar em conta a prévia ponderação efetuada anteriormente pela autoridade competente para a instituição da regra.

\section{Princípios materiais e formais e margens de ação epistêmicas}

Segundo a teoria dos princípios de Alexy, regras também possuem um caráter prima facie, porém distinto do caráter prima facie dos princípios. Os princípios ordenam que algo deva ser realizado na maior medida, conforme as possibilidades jurídicas e fáticas, não contendo, portanto, mandados definitivos, mas prima facie. As regras, por seu turno, exigem que se faça exatamente o que elas ordenam, contendo uma determinação no âmbito das possibilidades jurídicas e fáticas. Mas na decisão de um caso pode ser incluída uma cláusula de exceção em uma regra. Então esta perde seu caráter definitivo para a solução do caso, principalmente quando essa cláusula de exceção é levada a cabo sobre a base de um princípio. Assim, as regras acabam por perder seu caráter estritamente definitivo e assumem um caráter prima facie. Entretanto esse caráter prima facie é distinto do caráter prima facie dos princípios. Um princípio é afastado quando, no caso que se tem de decidir, o princípio oposto tem maior peso. No caso de uma regra, não basta afastá-la para que o princípio oposto tenha um peso maior do que o que a sustenta, sendo também necessário

\footnotetext{
${ }^{19}$ STF. IF 2.915-5/SP. Pleno, rel. min. Marco Aurélio. Rel. p/ ac. min. Gilmar Mendes, por maioria. DJ de
} 28-11-2003. Ementário nº 2.134-1. 
afastar os chamados "princípios formais" - que estabelecem que as regras que são impostas por uma autoridade legítima devem ser seguidas. Em um ordenamento jurídico, o caráter prima facie das regras irá variar conforme o peso que se confere a esses "princípios formais". As regras só teriam o mesmo caráter prima facie dos princípios se nenhum peso fosse atribuído aos "princípios formais".

Para explicitar esse modelo, Alexy recorre à noção de margem de ação epistêmica. Para Alexy, a pergunta sobre a existência de margens epistêmicas aparece quando são incertos os conhecimentos acerca do que está ordenado, proibido ou confiado à discricionariedade do legislador pelos direitos fundamentais, cuja causa pode advir da falta de certeza sobre premissas empíricas ou sobre premissas normativas. Sobre a falta de certeza sobre premissas empíricas, Alexy traz o exemplo da sentença do Tribunal Constitucional alemão, em que se questionou a legitimidade do legislador para proibir os produtos derivados da cannabis. $\mathrm{O}$ tribunal entendeu que não se dispunha de conhecimentos científicos suficientes para afirmar a correção de uma ou outra alternativa, porém reconheceu que o legislador possuía uma margem de ação epistêmica do tipo empírico. Já a margem de ação epistêmica do tipo normativo ocorre quando "não se tem certeza sobre qual é a maneira mais apropriada para sopesar os direitos fundamentais que estão em jogo, e se reconhece que o legislador possui um determinado marco dentro do qual pode adotar uma decisão segundo sua própria valoração". Traz como exemplo a sentença do Tribunal Constitucional alemão que tratou da proteção dos trabalhadores na demissão.

Se tomados isoladamente, os princípios de direito fundamental não aceitariam uma margem de ação cognitiva para o legislador; quando a verdade não pudesse ser estabelecida, a decisão só poderia ser tomada a partir das premissas empíricas favoráveis ao direito fundamental. Mas aí entra em jogo o princípio formal da competência do legislador para decidir, que se legitima pelo princípio democrático, que impõe que o legislador democraticamente legitimado seja, na maior medida possível, quem tome as decisões importantes para a comunidade. Surge então uma colisão entre o princípio de direito fundamental e o princípio formal, que pode ter duas soluções extremas: ou bem se entende uma primazia absoluta do princípio de direito fundamental sobre o segundo, ou bem se entende a primazia do princípio formal sobre o primeiro. A primeira solução não se pode admitir, pois seria incompatível com o princípio democrático e o princípio da separação dos poderes; por outro lado, a segunda opção também não é válida, pois abriria uma permissão para o legislador levar a cabo intervenções extraordinariamente extensas sobre os direitos fundamentais. A solução, portanto, estaria em uma proposta intermediária.

Voltando os olhos para a nossa Constituição, percebemos que ela também não admite nenhum dos modelos extremos para a solução desse conflito. De um lado, 
há um extenso rol de direitos fundamentais (CF, art. $5^{\circ} \mathrm{e}$ outros dispositivos esparsos), mas, por outro, há uma expressa divisão de competências, cabendo primariamente aos poderes Legislativo e Executivo o estabelecimento de leis e políticas para a concretização desses direitos fundamentais (CF, arts. 48 e segs., e art. 84). A Constituição estabelece direitos fundamentais que vinculam o legislador, mas o faz deixando uma razoável margem de ação.

Para se chegar a um modelo intermediário razoável, devem ser levadas em conta as margens de ação epistêmicas do tipo empírico e do tipo normativo descritas. Em relação às margens de ação empíricas, conforme Alexy, "quanto mais intensa seja uma intervenção em um direito fundamental, tanto maior deve ser a certeza das premissas que sustentam a intervenção".$^{20}$ A margem de ação empírica disponível ao legislador varia, assim, de acordo com a intensidade da intervenção efetuada sobre o direito fundamental.

Quanto à margem de ação normativa, irá variar de acordo com a resultante das forças exercidas pelos princípios em confronto. Os princípios materiais exercem uma pressão ou peso para que sejam alcançados os fins neles previstos, mas em certos casos há um verdadeiro empate ou pelo menos uma situação em que não é possível afirmar com certeza qual é o princípio que prevalece. Nesses casos, "os princípios materiais não têm força para evitar que o princípio da competência decisória do legislador democraticamente legitimado conduza a uma margem epistêmica para a ponderação".

\section{Ponderação e especificidade dos princípios}

Tarefa importante e preliminar à ponderação entre princípios é a escolha dos princípios que serão contrapostos ao princípio que sustenta a aplicação da regra. Como bem sistematizaram Luís Roberto Barroso e Ana Paula de Barcellos, os princípios constitucionais podem ser escalonados em graus de generalidade e abrangência. Há os princípios fundamentais, que expressam as principais decisões políticas no âmbito do Estado, que determinam sua estrutura essencial, tais como os princípios federativo, republicano e do Estado democrático de direito $(\mathrm{CF}$, art. 1, caput). Os princípios gerais são importantes especificações dos princípios constitucionais, mas têm um menor grau de abstração, permitindo mais facilmente a identificação do seu núcleo. São princípios gerais, por exemplo, os princípios da liberdade, da legalidade e da isonomia ( $\mathrm{CF}$, art. $5^{\circ}$ ). Por fim, há princípios setoriais, que presidem um específico conjunto de normas afetas a determinado tema, como

\footnotetext{
${ }^{20}$ Essa proposição é denominada por Alexy de "segunda lei da ponderação".
} 
o da legalidade administrativa (CF, art. 37, caput) e da capacidade contributiva (CF, art. 145, § 1ํ). Os princípios setoriais têm menor campo de irradiação, mas são supremos no seu âmbito de atuação.

Assim, quanto mais geral o princípio, maior sua abrangência, porém menor a sua definição. $\mathrm{O}$ princípio da dignidade da pessoa humana pode indicar a absolvição do acusado, mas também pode dar fundamento à sua condenação, como demonstrado por Santiago Nino. Quando se confronta a aplicação de uma regra, o intérprete deve primeiramente buscar os princípios setoriais que regem a matéria, pois eles permitem uma maior determinação - e consequentemente maior objetividade - no discurso jurídico. Para o afastamento de uma regra, não deve ser apontado um princípio geral, a menos que não haja outro mais específico para abranger o caso concreto.

\section{Superação de regras, estrutura do Estado e direitos fundamentais}

Quando estamos diante de uma regra estabelecida pelo legislador, existe um princípio formal que lhe dá sustentação: o princípio que impõe que o legislador democraticamente legitimado seja, na maior medida possível, quem tome as decisões importantes para a comunidade. Temos, assim, o princípio da livre conformação do legislador.

Se estamos diante de uma regra substancialmente válida, sustentada por um princípio constitucional, que em abstrato não viola outras normas constitucionais, a superação dessa regra diante de um caso concreto só pode ser admitida se sua aplicação vai de encontro a um direito fundamental ou compromete a própria estrutura do sistema jurídico.

As regras funcionam também como instrumentos para alocação de poder. Um tomador de decisões não limitado por regras tem o poder, a autoridade, e a jurisdição para levar todas as coisas em conta e, por outro lado, aquele limitado pelas regras perde ao menos um pouco dessa jurisdição. O estabelecimento de regras produz uma alocação de poder intertemporal, diminuindo o grau de diferença que a mudança de pessoal em uma instituição pode causar, principalmente em tribunais de apelação, mas também em corpos legislativos. Veja-se, por exemplo, o conjunto de regras constitucionais que limita o poder de legislar e, mais ainda, o poder de alterar a Constituição, evitando que as mudanças sejam muito fáceis ou muito frequentes.

A Constituição brasileira confere primariamente ao legislador a competência para a concretização dos direitos fundamentais, o que se dá mediante a edição de regras. Para superá-las, não basta a mera contraposição de um princípio que esta- 
ria sendo invadido no caso concreto. O princípio trazido em contraposição à regra deve garantir um direito fundamental ou então a própria integridade do sistema jurídico, como fazem os princípios que estruturam o Estado democrático de direito.

\section{Superação de regras e hierarquia das normas}

Uma condição apontada por Ávila é que a superação de uma regra pela contraposição de um princípio só é possível quando este é de hierarquia superior à da regra. Assim, uma regra estabelecida em ato regulamentar só pode ser suplantada pela razão oriunda de um princípio legal ou constitucional. No mesmo raciocínio, uma regra legal só pode ser superada em razão de um princípio constitucional.

Colocada assim, a exigência não apresenta problemas. Todavia, como proceder no caso das regras constitucionais? As regras constitucionais não admitem superação?

A tese da hierarquia entre as normas da Constituição não tem sido acatada pelo $\mathrm{STF}^{21}$ e nem é possível aplicar o modelo de Alexy no confronto entre regras e princípios da própria Constituição, pois o princípio material não seria capaz de suplantar o princípio formal que sustenta a regra, já que esse princípio formal também é o que sustenta o princípio contraposto, dentro de um modelo positivista. De outra ponta, regras constitucionais também podem ser superadas, como foi o caso da IF no 2.915-5. Há regras constitucionais que formalmente estão na Constituição, mas estabelecem apenas direitos secundários, que muito bem poderiam constar da legislação ordinária, e que somente foram incluídas no texto constitucional por força do pacto político firmado na ocasião da assembleia constituinte. Não se vislumbra, portanto, impedimento à superação dessas regras em um determinado caso concreto.

Assim, entendemos que o critério da hierarquia superior do princípio não é um critério consistente, motivo pelo qual preferimos o critério do princípio de direito fundamental ou de garantia do sistema, explicado anteriormente.

\section{Parâmetros para a superação de uma regra pelo confronto de um princípio}

Com base nessas premissas, formulamos os seguintes parâmetros para a superação de uma regra pela oposição de um princípio jurídico:

\footnotetext{
${ }^{21}$ STF. ADI 815/DF, Pleno, rel. min. Moreira Alves, DJU de 10-5-1996.
} 
o princípio material contraposto ao princípio material que justifica a regra deve ser o mais específico possível;

o princípio material contraposto ao princípio material que justifica a regra deve ser um princípio de direito fundamental ou de garantia do sistema jurídico;

o princípio material contraposto deve ter, no caso concreto, um peso maior do que o princípio material que sustenta a regra;

o princípio material contraposto deve, no caso concreto, superar o princípio formal que sustenta a regra.

Utilizando tais parâmetros, criamos balizas que diminuem a subjetividade na aplicação dos princípios jurídicos e, também, podemos reconstruir as decisões judiciais em que uma regra foi superada em um caso concreto por razões advindas de um princípio jurídico, verificando sua justeza dentro de uma argumentação jurídica coerente.

Vejamos o caso da IF no $2.915 / D F$, exposto, em que o STF afastou a regra do art. 34, VI, da CF, pela aplicação de um princípio jurídico. No voto do ministro Gilmar Mendes podemos verificar que o primeiro parâmetro foi atendido, pois foi selecionado um princípio específico que rege a matéria, qual seja, o princípio da não intervenção, abstraído do art. 34, caput, da CF. Outro princípio selecionado, também atendendo ao requisito da especificidade, foi o da reserva do possível. Note-se que o ministro Gilmar Mendes poderia ter escolhido o princípio do estado de direito ou mesmo o princípio federativo, mas isso só contribuiria para uma maior indefinição e um maior subjetivismo da decisão, haja vista a abrangência e a menor especificidade desses princípios. O segundo requisito também foi atendido, pois os princípios contrapostos estão ligados diretamente à própria estrutura do sistema jurídico e do estado de direito. A questão se complica quanto ao terceiro e ao quarto requisitos, tendo em vista que a regra superada também sustenta o estado de direito, é específica e foi instituída pelo próprio legislador constituinte originário, o que lhe dá uma força que não pode ser meramente ignorada.

No que tange ao maior peso do princípio da não intervenção, fica difícil argumentar pela existência de uma margem de ação epistêmica normativa, pois o inciso VI do art. 34 da CF abre uma específica exceção ao disposto no seu caput. Abrese, porém, uma margem de ação epistêmica empírica relativamente ao princípio da reserva do possível, pois ficou comprovado que o Estado não teria condições de arcar com o pagamento de todos os precatórios alimentares sem comprometer outros serviços públicos. Mas, ainda restaria superar o princípio formal que sustenta a própria regra constitucional do inciso VI do art. 34 que, dada a sua origem, tem uma força muito grande. A saída adotada pelo tribunal, como ocorre na maioria 
desses casos dificílimos, foi reconstruir a regra ad hoc, passando a fixar o sentido do dispositivo da seguinte forma: a desobediência à ordem judicial que justifica a intervenção é a desobediência dolosa, que não se configura quando o Estado não paga os precatórios por ausência de recursos. ${ }^{22}$

A falha da decisão do STF, no nosso entendimento, foi não ter levado em conta o princípio formal que sustenta a regra afastada. Se o tribunal tivesse levado esse princípio em consideração, teria maiores dificuldades em superar a regra com base em um argumento consequencialista, o que poderia ter conduzido a uma decisão intermediária e mais racional. Por exemplo, a intervenção poderia ser limitada a que o Estado apresentasse um programa de pagamento dos precatórios, que não necessariamente deveriam ser pagos em único exercício, mas dentro das possibilidades financeiras. Não poder pagar tudo de uma vez é diferente de não poder pagar alguma coisa, ou de ir pagando aos poucos. Assim, a decisão do STF, por não atentar para a força da regra oriunda do ato que a instituiu, acabou por dar uma permissão para a inadimplência dos estados em relação aos credores particulares.

\section{Conclusões}

Procuramos demonstrar neste artigo que as regras jurídicas são superáveis, ou seja, ainda que reunidas as condições para sua aplicação, mesmo assim elas podem não ser aplicadas em razão da excepcionalidade do caso ou da contraposição de um princípio. Afasta-se, assim, a ideia de Dworkin quanto ao caráter "tudo ou nada" das regras jurídicas.

A não aplicação das regras pode resultar de várias causas, notadamente a falta das condições para sua aplicação, como a validade, a existência, a eficácia e a incidência. Todavia, esses casos, inclusive o de não incidência qualificada pela incidência de uma regra de exceção, não se confundem com a superação da regra jurídica. Na superação, inevitavelmente haverá o recurso a argumentos não institucionais ou consequencialistas.

A superação da regra advém da sua própria natureza, pois sendo uma generalização do passado com pretensão de resolução de um caso futuro, fundada na relação de probabilidade com uma justificação almejada, pode se ver diante de experiências recalcitrantes, em que a generalização é afastada por razões surgidas no caso concreto.

\footnotetext{
${ }^{22}$ Este é o chamado "dilema da exigência de racionalidade". O comportamento racional do juiz exige que ele atue conforme o direito, mas que também aprecie a consequência de suas decisões. Quando essas duas exigências colidem, não raramente o juiz opta por modificar a descrição dos fatos antecedentes da norma geral, de modo que ela não seja aplicada ao caso.
} 
As razões fornecidas pela regra são entrincheiradas, pois resistem à alteração ante a experiências recalcitrantes, mas mesmo assim são superáveis. As regras, portanto, são razões prima facie para a ação, e não razões definitivas, porém apresentam uma força maior, pois para superá-las devem ser vencidas as razões que lhe são subjacentes, bem como as razões que levaram à sua instituição.

Para a superação da regra, requer-se a demonstração de que a excepcionalidade do caso exige que o sistema jurídico positivo seja colocado em um segundo plano e que se busque uma solução específica fora do sistema para resolvê-lo. Essa demonstração ou justificação pode estar baseada na própria finalidade subjacente à regra ou nos princípios superiores a ela. Quando se enfoca a finalidade subjacente à regra, a superação pode ser explicada pela redução teleológica ou do postulado da razoabilidade. A superação de uma regra também pode ser justificada pelo recurso a um princípio superior. Nesse caso, a aplicação da regra conduz a um estado de coisas que se opõe ao estado de coisas perseguido por outro princípio.

Em qualquer dos enfoques, devem ser observados certos parâmetros argumentativos. A utilização desses parâmetros cria balizas que diminuem a subjetividade na aplicação dos princípios jurídicos e que permitem reconstruir as decisões judiciais em que uma regra foi superada em um caso concreto. Obviamente, não há como afastar toda a discricionariedade possível nem atender ao ideal de Dworkin de encontrar uma única resposta correta para cada caso. Esse é um conflito inerente ao direito e inafastável da argumentação jurídica: a tensão entre justiça e segurança jurídica.

\section{Referências}

AARNIO, Aulis. La tesis de la única respuesta correcta y el principio regulativo del razonamiento jurídico. Doxa, Alicante, n. 8, p. 23-38, 1990.

ALEXY, Robert. Teoria da argumentação jurídica. A teoria do discurso racional como teoria da justificação jurídica. Tradução de Z. H. S. Silva. São Paulo: Landy, 2001.

. Epílogo a la teoría de los derechos fundamentales. Revista Española de Derecho Constitucional, ano 22, n. 66, p. 13-64, 2002a.

. Teoria de los derechos fundamentales. Tradução de Ernesto Garzón Valdés.

Madrid: Centro de Estúdios Políticos e Constitucionales, 2002b.

ARISTÓTELES. Ética a Nicômaco. Tradução de P. Nassetti. São Paulo: Martins Claret, 2002.

ATALIBA, Geraldo. Hipótese de incidência tributária. 6. ed. São Paulo: Malheiros, 2002. 
ATIENZA, Manuel. As razões do direito. Tradução de Maria C. G. Cupertino. São Paulo: Landy, 2002.

; MANERO, Juan Ruiz. Las piezas del derecho. Barcelona: Ariel, 1996.

ÁVILA, Humberto. Teoria dos princípios. Da definição à aplicação dos princípios jurídicos. São Paulo: Malheiros, 2003.

. Sistema constitucional tributário. São Paulo: Saraiva, 2004.

Argumentação jurídica e imunidade do livro eletrônico. Revista Diálogo Jurídico, v. 1, n. 5, Salvador. Disponível em: <www.direitopublico.com.br>. Acesso em: 20 mar. 2004.

BARROSO, Luís Roberto. O direito constitucional e a efetividade de suas normas. Rio de Janeiro: Renovar, 2001.

; BARCELLOS, Ana Paula de. O começo da história. A nova interpretação constitucional e o papel dos princípios no direito brasileiro. Interesse Público, n. 19, p. 51-80, 2003.

BAYÓN, Juan Carlos. Sobre a racionalidad de dictar e seguir reglas. Doxa, Alicante, n. 19 , p. 143-162, 1996.

BOBBIO, Norberto. Teoria da norma jurídica. Tradução de F. P. Baptista e A. B. Studatti. Bauru: Edipro, 2001.

CALVO, Raúl; VERNIER, Carlos. Racionalidad de las justificaciones consecuencialistas en las decisoes judiciales. Isonomia, Alicante, n. 19, p. 155-182, 2003.

DWORKIN, Ronald. Taking rights seriously. Cambridge: Harvard University Press, 2001.

FIGUEROA, Alfonso García. La incidencia de la derrotabilidad de los principios iusfundamentales sobre el concepto de derecho. Diritto $\mathcal{E}$ Questione Publiche, n. 3, p. 197-227, 2003.

HAGE, Jaap. Reasoning with rules. Na essay on legal reasoning and its underlying logic. Dordrecht: Kluwer, 1997.

. Law and Coherence. Ratio Juris, v. 17, n. 1, p. 87-105, Mar. 2004.

HART, Herbert L. A. O conceito de direito. 3. ed. Tradução de A. R. Mendes. Lisboa: Calouste Gulbenkian, 2001.

KELSEN, Hans. Teoria pura do direito. Tradução de J. B. Machado. São Paulo: Martins Fontes, 2000.

LARENZ, Karl. Metodologia da ciência do direito. 3. ed. Tradução de José Lamego. Lisboa: Fundação Calouste Gulbenkian, 1997. 
NINO, Santiago. Ética y derechos humanos. 2. ed. Buenos Aires: Astrea, 1989.

NOVELLI, Flávio Bauer. Norma constitucional inconstitucional? A propósito do art. 2, § 2을 da Emenda Constitucional n 3/93. Revista de Direito Administrativo, Rio de Janeiro, n. 199, p. 21-57, 1995.

PECZENIK, Aleksander. On law and reason. Dordrecht: Kluwer, 1989.

. Los principios jurídicos según Manuel Atienza Y Juan Ruiz Manero. Doxa, Alicante, n. 12, p. 327-331, 1992.

. Derecho y razón. Tradução de Ernesto Garzón Valdez. México: Fontanamara, 2000 .

PERELMAN, Chaïm. Lógica jurídica. Tradução de V. K. Pupi. São Paulo: Martins Fontes, 2000.

PONTES DE MIRANDA. Tratado de direito privado. 2. ed. Campinas: Bookseller, 2000. Parte geral tomo I.

ROSS, Alf. Direito e justiça. Tradução de E. Bini. São Paulo: Edipro, 2003.

SCHAUER, Frederik. Playing by the rules. A philosophical examination of rulebased decision-making in law and in life. Oxford: Clarendon, 1991.

ZAGREBELSLY, Gustavo. El derecho dúctil. Ley, derechos, justicia. Tradução de Marina Gascón. 3. ed. Madrid: Trotta, 1999. 